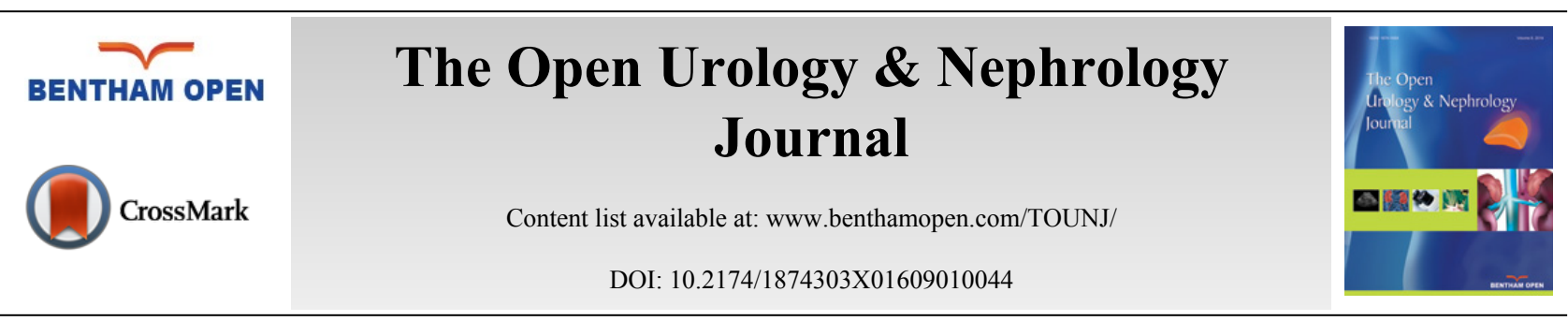

\title{
Monocyte Chemotactic Protein-1 (MCP-1) as a Predictor of Prolonged Urinary Incontinence After Radical Prostatectomy
}

\author{
Michael A. Liss ${ }^{1, *}$, Thomas E. Ahlering ${ }^{2}$, Blanca Morales ${ }^{2}$, Adam Gordon², Kathryn Osann ${ }^{3}$, \\ Douglas Skarecky², Achim Lusch ${ }^{2}$, Frank Zaldivar ${ }^{4}$ and Gamal M. Ghoniem ${ }^{2}$ \\ ${ }^{I}$ Department of Urology, University of Texas Health Science Center San Antonio, TX, USA \\ ${ }^{2}$ Department of Urology, University of California-Irvine, CA, USA \\ ${ }^{3}$ Department of Medicine, University of California-Irvine, CA, USA \\ ${ }^{4}$ Institute for Clinical and Translational Science, University of California-Irvine, CA, USA
}

Received: August 8, 2015

Revised: November 30, 2015

Accepted: December 6, 2015

\section{Abstract:}

Objectives:

To investigate monocyte chemotactic protein-1 (MCP-1) as a novel urinary biomarker to predict prolonged post prostatectomy incontinence.

\section{Methods:}

Men submitted urine samples prior to robotic radical prostatectomy. MCP-1 values were derived using an ELISA test. Pad usage at 7 , 30 , and 60 days were documented by patient post cards mailed when zero pads was reached. The primary outcome was defined as no incontinence pad usage at 30 days at prostatectomy.

\section{Results:}

After exclusions, 76 patients were included in analyses. Continence was reached by $29 \%(22 / 76), 56 \%(42 / 76)$, and (75/76) $98 \%$ at 7 , 30 , and 60 days, respectively. The average MCP-1 $(p=0.258)$ was not different between the continent and incontinent groups. Highest quartile of MCP-1 (MCP $>166 \mathrm{pg} / \mathrm{mL})$ and normalized MCP-1 (MCP-1/TV $>0.53)$ noted a significant delay in continence at 30 days ( $p=0.050$ and $p=0.003)$. Only $26 \%(5 / 19)$ in the highest MCP1/TV quartile were continent, whereas $65 \%(37 / 57)$ of men in the 3 lower quartiles reached zero pad continence $(p=0.003)$. In a logistic regression model the highest quartile of MCP1/TV had a significant chance of being incontinent at 30 days (OR $0.22 ; 95 \%$ CI $0.058-0.80 ; p=0.022$ ).

\section{Conclusion:}

MCP-1/TV is a urinary biomarker that may predict prolonged urinary incontinence after radical prostatectomy.

Keywords: Incontinence, overactive bladder, prostate cancer, prostatectomy, quality of life.

\section{INTRODUCTION}

Prostate cancer, the most common non-cutaneous malignancy prevalent in males, is the $2^{\text {nd }}$ leading cause of death compared to other cancers in men [1]. Radical prostatectomy is one of the treatment options available for organconfined disease. Postoperative incontinence is a common side effect after prostatectomy that can severely impact quality of life [2 - 6]. The pathophysiology of incontinence is largely due to extrinsic sphincter insufficiency; however

\footnotetext{
* Address correspondence to this author at the Department of Urology, UTHSCSA, 7703 Floyd Curl Drive, San Antonio, TX 78229 USA; E-mail: mliss008@gmail.com
} 
may be exacerbated by various other factors [7].

As divulged by a recent review of the literature, other factors such as detrusor overactivity, reduced bladder capacity, and impaired detrusor contractility can be pivotal for developing bladder dysfunction after prostatectomy [8]. Moreover, de novo detrusor instability after prostatectomy can lead to overactive bladder (OAB) symptoms, which may be detectable by urodynamic evaluation [9]. Currently, lack of the knowledge on the preoperative biomarkers alluding to postoperative incontinence is a limiting factor in the counseling process because the information may potentially be used as an additional component at the time of counseling. To this end, a previous study using a proteomics chip based analysis of urinary cytokine expression demonstrated that OAB group expressed Monocyte Chemotactic Protein-1 (MCP-1) two-fold higher than UTI population and controls, thus suggesting MCP-1 to be a potential target for an OAB biomarker [10]. Based on these premises, we conducted a clinical study to assess whether urinary MCP-1 can be a potential preoperative biomarker associated with the outcome of 30-day urinary continence after robotic radical prostatectomy (RRP).

\section{METHODS}

\section{Patient Population and Study Design}

After institutional review board approval, we enrolled biopsy proven prostate cancer patients who were undergoing pre-operative evaluation for robotic assisted radical prostatectomy. One hundred twenty men volunteered to provide urine samples after going through informed consent. For all these patients, serum laboratory studies, urine analysis, uroflowmetry results, and post-void residual were recorded. In order to minimize differences in surgical technique, we only enrolled patients in which the robotic radical prostatectomy was performed by a single surgeon (TA). The sparing technique was decided by the primary surgeon on a case-by-case basis and the reasons for such decision were documented. Patients were sequentially enrolled to evaluate both cancer specific and incontinence specific preoperative urinary biomarkers. Therefore, patients were excluded from final analysis if they had previous radiation therapy $(n=2)$, pT4 disease $(n=1)$, chronic inflammation on final pathology $(n=11)$, active urinary tract infection, or were taking anticholinergic medication preoperatively $(n=25)$. Patients from non-white ethnicity were excluded because of very limited numbers $(n=4)$.

\section{Questionnaires}

The patient also completed the International Index of Erectile Function (IIEF-5) and the International Prostate Symptom Score (IPSS) questionnaires, including the urinary quality of life (QOL) question. By and large, the primary components to urinary incontinence recovery after radical prostatectomy are age, sexual function (IIEF-5) and obesity [11]. Specifically the inquiries involving IIEF-5 score focus on the confidence of an erection, erection firmness, maintenance of an erection, and sexual satisfaction. On the other hand, the IPSS score evaluates preoperative obstructive or urgency symptoms that may contribute to postoperative incontinence.

\section{Urine Sample Collection and Processing}

The urine samples were collected when the participants had a strong desire to void with "extremely full" bladders. After the patients voided, the data on uroflowmetry characteristics such as the volume of void (VV), peak flow rate (PFR) and postvoid residual (PVR) were collected. The total volume in the bladder was calculated by adding VV to PVR. The urine samples were placed on ice immediately after collection and transferred to the laboratory for the preparation to store them appropriately. Routinely, the urine samples were centrifuged at $3000 \mathrm{~g}$ for $10 \mathrm{~min}$ at $4^{\circ} \mathrm{C}$ to collect the supernatant and $1.5 \mathrm{~mL}$ aliquots were preserved at $-80^{\circ} \mathrm{C}$.

\section{Determination of Monocyte Chemotactic Protein - 1 level}

The Quantikine Human MCP-1 Immunoassay (R\&D Systems, Minneapolis, MN) is a 3.5-4.5 hour solid phase ELISA designed to measure MCP-1 in cell culture, serum, plasma, and urine. All reagents were prepared as specified by the manufacturer's instructions, which include well washing of the samples followed by incubation for 30 minutes at room temperature by addition of $200 \mu \mathrm{L}$ of substrate into each well. Finally, a stop solution was added to the wells and then optical density of each well was assessed by using a microplate reader set at $450 \mathrm{~nm}$. All measurements were performed in duplicate and the average was used to subtract from the zero standard optical density. From the manufacturer the initial evaluation on 37 healthy volunteers demonstrated an average of $211 \mathrm{pg} / \mathrm{mL}$ (range 42-410) MCP-1 protein. However no further information regarding age, gender, or urinary symptoms are provided. Previous 
studies have normalized urinary biomarkers with urinary creatinine and/or specific gravity [12]. We include the total urinary volume as dilution factor of the protein that can potentially vary and can be used to normalize the results.

\section{Follow-Up}

We asked participants to return pre-stamped postcards when they achieved pad free status date and/or keep a daily log of their progress, which is standard of care in our department. Patients also kept continence logs for the first week after the catheter was removed. Patients who did not reach continent status or did not return logs, were contacted by phone for updates. At the end of the study period ( 3 months post-operatively) patients with missing data were contacted via telephone.

Table 1. Demographics of 30 Day continence populations.

\begin{tabular}{|c|c|c|c|c|}
\hline \multirow[b]{4}{*}{ Demographic } & \multicolumn{2}{|c|}{ Continence at 30 Days } & & \\
\hline & \multirow{2}{*}{\begin{tabular}{|c|} 
Yes \\
$\mathrm{N}=42$ \\
\end{tabular}} & \multirow{2}{*}{\begin{tabular}{|c|} 
No \\
$\mathbf{N}=34$ \\
\end{tabular}} & & \\
\hline & & & & \\
\hline & Mean (SD) & Mean (SD) & $P$ value & Statistical Test \\
\hline Age & $60.8(7.1)$ & $61.8(7.1)$ & 0.528 & $t$ test \\
\hline Prostate Specific Antigen & $5.4(2.3)$ & $6.7(5.5)$ & 0.164 & $t$ test \\
\hline American Urologic Association Symptom Score & $6.1(6.2)$ & $7.7(6.2)$ & 0.237 & $t$ test \\
\hline Sexual health inventory for Men (SHIM) & $22.8(3.5)$ & $18.9(8.0)$ & 0.008 & $t$ test \\
\hline Body Mass Index (BMI) & $27.3(3.6)$ & $27.3(2.6)$ & 0.996 & $t$ test \\
\hline Voided Volume (mL) & $396(227)$ & $312(195)$ & 0.092 & $t$ test \\
\hline Post Void Residual (mL) & $96(89)$ & $85(64)$ & 0.562 & $t$ test \\
\hline Total bladder volume (TV) (mL) & $482(260)$ & $397(224)$ & 0.098 & $t$ test \\
\hline Prostate Weight (gm) & $49.1(41.4)$ & $55.5(39.5)$ & 0.105 & $t$ test \\
\hline Urinary Creatinine & $34.2(98.7)$ & $43(39.5)$ & 0.171 & Mann-Whitney \\
\hline Monocyte Chemotatic Protein $1(\mathrm{ng} / \mathrm{mL})$ & $164.7(177.1)$ & $108.4(98.7)$ & 0.208 & Mann-Whitney \\
\hline \multirow[t]{2}{*}{ Monocyte Chemotactic Protein 1 (ng/mL) / Total bladder volume } & $0.342(0.450)$ & $0.724(1.13)$ & 0.085 & Mann-Whitney \\
\hline & Number $(\%)$ & Number $(\%)$ & & \\
\hline Bilateral Nerve Sparing & $27(79.4)$ & $40(95.2)$ & 0.070 & Fishers Exact \\
\hline Smoker & $2(5.9)$ & $2(4.8)$ & 1.0 & Fishers Exact \\
\hline Diabetes & $1(2.9)$ & $0(0)$ & 0.447 & Fishers Exact \\
\hline Statins & $10(29.4)$ & $20(47.6)$ & 0.157 & Fishers Exact \\
\hline Pathologic Stage & & & 0.433 & Fishers Exact \\
\hline$p \mathrm{~T} 2$ & $13(31.0)$ & $7(20.6)$ & & \\
\hline$p \mathrm{~T} 3$ & $29(69)$ & $27(79.4)$ & & \\
\hline
\end{tabular}

\section{Statistical Analysis}

For purposes of this study, continence was defined as no pads. Our primary outcome was 30 day continence. The primary predictor variable was Moncycte chemotactic protein 1 (MCP-1) which was compared using the $t$-test between continent $v s$. incontinent men at specific time points. The cut off values were not known preoperatively; therefore, quartiles are used to identify differences at extremes. The association between MCP-1 and other variables were explored with the Spearman correlation coefficient or Mann-Whitney test. Specifically we performed correlation of MCP-1 to the normalization variables of total urinary volume or urinary creatinine. As secondary outcomes, we also investigated continence at day 7 (early) and day 60 (delayed) associated with MCP-1. In general, continence was evaluated using the Chi-squared test at 7 day, 30 day, and 60 day time points. The univariate analysis was done with Chi-Squared tests and the multivariate analyses were performed with logistic regression.

\section{RESULTS}

After exclusions, 76 patients were included in analyses. Demographics of the group are presented in Table $\mathbf{1 .}$ Approximately in $80 \%(61 / 76)$ of cases, patients followed the log or sent post cards of their zero pad date, while remaining 20\% (15/76) patients were contacted by either telephone or email. The primary outcome of continence consisting of using zero pads was reached by 29\% (22/76), 56\% (42/76), and (75/76) 98\% at 7, 30, and 60 days, respectively. Comparing incontinent and continent men at 30 days after prostatectomy, the IPSS score (7.7 vs. 6.1; $p=0.237)$, urgency question $(1.5 v s .1 .1 ; p=0.283)$, or quality of life question (1.0 vs. $0.7 ; p=0.317)$ were not associated 
with urinary continence. The urgency question (none $=0 v s$. any $=1$ ) of the IPSS score did not demonstrate any association with time to urinary continence ( 36 vs. 34 days; $p=0.858)$. Furthermore, the correlations between MCP1 and other variables were investigated. Of note, the urinary creatinine $(\mathrm{r}=0.21 ; p<0.001)$ and the total bladder volume $(\mathrm{r}=-0.56 ; p<0.001)$ showed the highest correlation with MCP-1. Because creatinine excretion may vary due to diurnal creatinine production, physical activity, emotional stress, diet, muscle mass (hence age, sex, and body weight variation), and disease state, we chose to correct the MCP-1 value using the better correlative value of total urine volume, and then accounted for creatinine in multivariable analysis [13]. Other variables significantly correlated with MCP-1 include the sexual health inventory for men (IIEF-5; $\mathrm{r}=-0.24 ; p=0.037$ ) and the American Urological Association symptom score (IPSS; $\mathrm{r}=0.25, p=0.030$ ). No significant correlations were identified between MCP-1 and other demographic variables.

We investigated the associations with 30 day continence in univariant analysis (Table 1). We identified no significant difference in 30-day continence between the average MCP-1 $(p=0.258)$ or MCP after adjusting for bladder volume (MCP1/TV; $p=0.14)$. Additionally, bladder volume was larger in those who were continent at 30 days but was not statistically significant (482 vs. 397, $p=0.098$ ). We then analyzed MCP by quartiles and comparing the highest quartile of MCP-1 (MCP > $166 \mathrm{pg} / \mathrm{mL})$ to all other quartiles, we noted a delay in continence $(p=0.050)$. Subsequently, we normalized MCP-1 values by dividing them by the total bladder volume (TV, mL) and obtained the highest quartile (MCP-1 >0.53). Comparing MCP-1/TV to all other quartiles, we again noted a significant delay in continence among patients with the highest quartile. At 30 days only $26 \%(5 / 19)$ in the highest MCP1/TV quartile were continent, whereas $65 \%(37 / 57)$ of men in the 3 lower quartile reached zero pad continence $(p=0.003)$ (Fig 1). Additionally, men in the highest MCP-1/TV quartile were also noted to have significantly higher incontinence at 7 days $(89.5 \% \mathrm{vs}$. 64.9\%; $p=0.041)$ compared to all other quartiles combined. At 60 days, the difference in continence rates for highest quartile of MCP1/TV vs. lower quartiles $(68.4 \%$ vs. $78.9 \%$; $p=0.350)$ was no longer statistically significant.

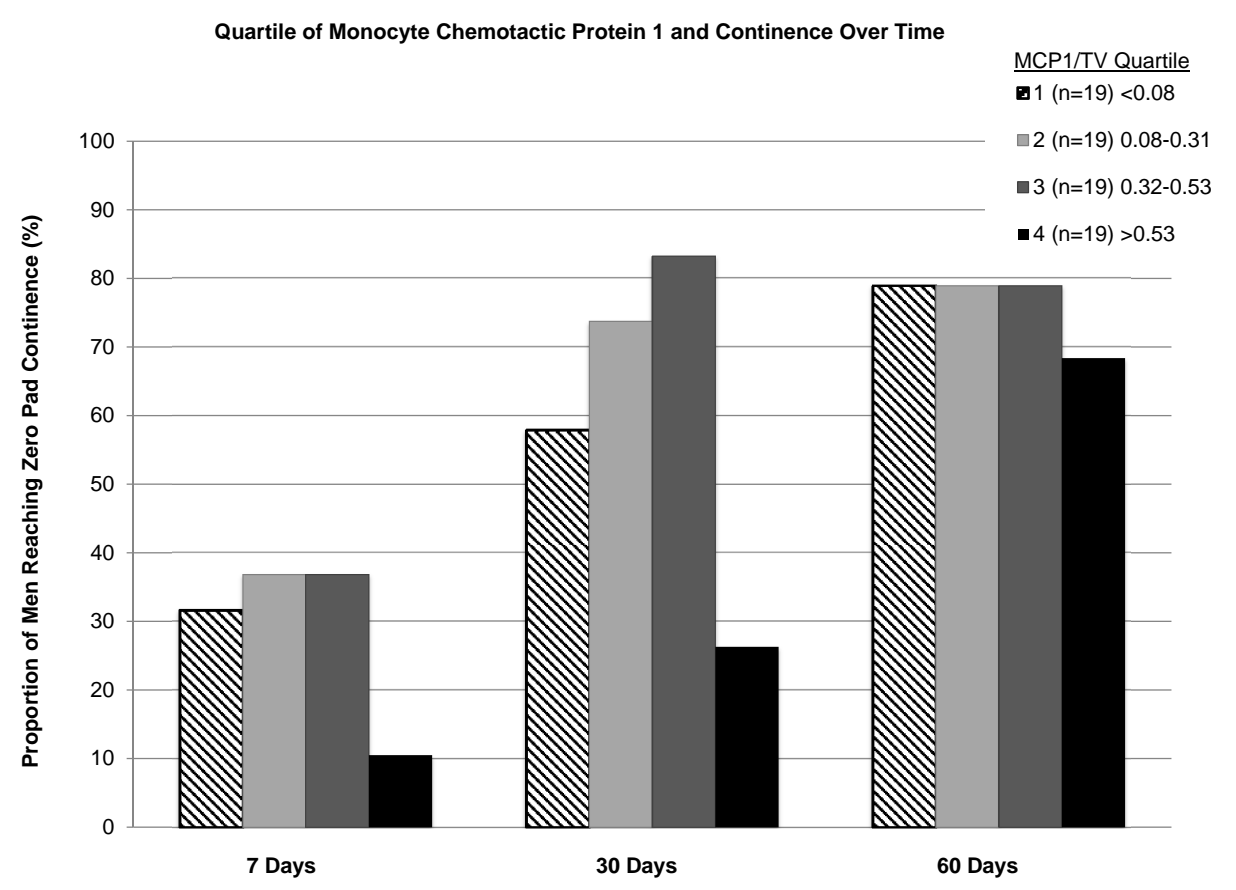

Fig. (1). Bar graph representing zero pad continence at selected time points for the highest quartile MCP-1/TV.

Next, a logistic regression model was developed including MPC1/TV (highest quartile vs. lower quartiles), and IIEF-5 as independent variables in the model. In addition, urinary creatinine was included in the model to account for urine concentration and bilateral nerve sparing was included as it trended to significance in univariant analysis. We noted that patients in the highest quartile of MCP-1/TV bear a significant risk of being incontinence at 30 days from robotic prostatectomy which is controlling other factors (OR $0.22 ; 95 \%$ CI $0.058-0.80 ; p=0.022$ ) (Table 2).

\section{DISCUSSION}

To summarize, our studies indicate that high preoperative levels of Monocyte chemotatic protein-1 corrected for total bladder volume may play a role in developing incontinence at 30 day. These findings further suggest that a 
preconditioned state of high inflammation may be present in some patients causing bladder pathology thus contributing to prolonged recovery of continence. Indeed our previous study leading to this investigation postulated that elevated expression of MCP-1 in patients with overactive bladder could contribute to incontinence [10]. Another important aspect of our investigation is the pinning down MCP-1/TV as a potential biomarker to identify subjects that can start medications early in the recovery process. It is expected that such patients may benefit more from OAB therapy prior to prostatectomy .

Table 2. Univariate and multivariate analysis achieving 30 day continence.

\begin{tabular}{|c|c|c|}
\hline Multivariant & OR (95\% CI) & P Value \\
\hline MCP1/TV $>0.53$ & $0.22(0.058-0.80)$ & 0.022 \\
\hline Urinary Creatinine & $1.00(0.99-1.02)$ & 0.785 \\
\hline Bilateral Nerve Sparing & $3.45(0.29-40.04)$ & 0.322 \\
\hline SHIM & $1.08(0.99-1.21)$ & 0.076 \\
\hline
\end{tabular}

At present, studies are indeed limited regarding anti-inflammatory therapy to prevent post-operative incontinence. However, rising interest in MCP-1 as a diagnostic or therapeutic target in other diseases may provide such opportunity. It will be quite prudent to undertake studies to test whether the ablation of MCP-1 prior to radical prostatectomy will diminish the extent of urinary incontinence. It is worth mentioning that CCR2 (chemokine receptor 2), which is the primary MCP-1 receptor, has been considered to be an important therapeutic target in treating the deleterious effects of myocardial infarction and acute kidney injury [14, 15]. Likewise, the same mechanism may be tested in a preprostatectomy cohort investigating urinary outcomes. Another evolving concept regarding reducing inflammation is hypothermia of the prostate via a rectal balloon at the time of surgery [16]. Our previous study is quite remarkable because all patients who received hypothermia during prostatectomy, had a significant reduction in post prostatectomy incontinence [17]. However, in this pilot study, we were unable to determine the true effect of hypothermia, specifically on MCP-1 because we did not measure intraoperative or postoperative MCP-1 levels.

Currently, surgeons are compelled to assess the bladder symptoms of the patients by using demographics and questionnaires prior to prostatectomy due to the lack of any specific biomarkers. In line with this, a systematic review and meta-analysis of post-prostatectomy incontinence reported associations with age, BMI $>30$, comorbidities, severity of lower urinary tract symptoms, and preoperative erectile function (IIEF-5) [18]. We also investigated these variables in our cohort and noted preoperative sexual function (IIEF-5) to be an exclusive albeit significant determinant of incontinence. To the contrary, our studies do not conform to the notion that one of the most significant factors for incontinence is the age of the patient. Our study enrolled many men of similar age group and revealed that age difference exerts a negligible effect on the incontinence in this study population [19]. Other preoperative indicators have been examined including ultrasound of pelvic muscles and MRI of membranous urethral length, however these would add to the current cost and may rely on other specialists [20, 21]. In all, a urinary biomarker, such as MCP-1 would be valuable because this could provide uniform, objective risk profile that may be used across various sites. At this stage, a larger study potentially in the context of a clinical trial to confirm the results of MCP-1 as a urinary biomarker to predict post-operative continence is further warranted. The information obtained from such a biomarker could weigh heavily in the discussion regarding radical prostatectomy expectations and an individualized treatment plan, which may include pre-operative pelvic therapy and early use of medications.

We are aware of the limitations of this study because of the small sample size and homogeneous nature of our population especially in the context of age and race/ethnicity. We specifically chose to use strict entry criteria for this pilot study to show proof of concept and obtain preliminary data to justify inclusion into a clinical trial. Additionally, urinary biomarkers can indicate substantial variability from day to day, hydration status, and a multitude of other factors [22]. We limited the evaluation of urinary biomarkers for post prostatectomy solely to MCP-1. However, we plan to further investigate other urinary biomarker such as nerve growth factor that has been demonstrated to be promising for detrusor over-activity [23]. Further study would need to seriously test preoperative MCP-1 at various time points prior to surgery and changes noted post operatively. Of note, the origin and causality of MCP-1 are beyond the scope of this study. In this pilot study, we did not deploy urodynamics peri-operatively to identify exact type of urinary incontinence. Overall, we feel the prospective nature and the addition of bladder volume are novel in post-prostatectomy incontinence. 


\section{CONCLUSION}

In addition to other factors, high levels of Monocyte chemotactic protein - 1 may be associated with delayed recovery of continence after radical prostatectomy. Comprehensively, additional investigations are absolutely critical to establish MCP-1 as a urinary biomarker to predict delayed post-prostatectomy continence preoperatively. Based on these premises we infer that further studies with lager and broader populations are pivotal for confirmation of the findings presented in this report.

\section{FUNDING}

Institute for Clinical and Translational Science, University of California-Irvine. The project described was supported by Grant Number UL1 RR031985 from the National Center for Research Resources (NCRR), a component of the National Institutes of Health (NIH), and the NIH Roadmap for Medical Research. Its contents are solely the responsibility of the authors and do not necessarily represent the official view of NCRR or NIH. Information on NCRR is available at http://www.ncrr.nih.gov/. Information on Reengineering the Clinical Research Enterprise can be obtained from http://nihroadmap.nih.gov. Dr. Liss is a member of the Cancer Therapy and Research Center of The University of Texas Health Science Center San Antonio an NCI Cancer Center supported by grant (P30 CA054174) and also is supported by the DOD. This work was supported by the Office of the Assistant Secretary of Defense for Health Affairs through the Prostate Cancer Research Program under Award No. W81XWH-15-1-0441. Opinions, interpretations, conclusions and recommendations are those of the author and are not necessarily endorsed by the Department of Defense.

\section{CONFLICT OF INTEREST}

Dr. Ahlering is a consultant for Astellas and Phillips Healthcare Dr. Gohniem is a speaker for Astellas and Allergan, consultant for Uroplasty.

\section{ACKNOWLEDGMENTS}

Declared None.

\section{REFERENCES}

[1] Jemal A, Bray F, Center MM, Ferlay J, Ward E, Forman D. Global cancer statistics. CA Cancer J Clin 2011; 61(2): 69-90. [http://dx.doi.org/10.3322/caac.20107] [PMID: 21296855]

[2] Liss MA, Osann K, Canvasser N, et al. Continence definition after radical prostatectomy using urinary quality of life: evaluation of patient reported validated questionnaires. J Urol 2010; 183(4): 1464-8. [http://dx.doi.org/10.1016/j.juro.2009.12.009] [PMID: 20171689]

[3] Sacco E, Prayer-Galetti T, Pinto F, et al. Urinary incontinence after radical prostatectomy: incidence by definition, risk factors and temporal trend in a large series with a long-term follow-up. BJU Int 2006; 97(6): 1234-41. [http://dx.doi.org/10.1111/j.1464-410X.2006.06185.x] [PMID: 16686718]

[4] Sebesta M, Cespedes RD, Luhman E, Optenberg S, Thompson IM. Questionnaire-based outcomes of urinary incontinence and satisfaction rates after radical prostatectomy in a national study population. Urology 2002; 60(6): 1055-8. [http://dx.doi.org/10.1016/S0090-4295(02)01989-1] [PMID: 12475669]

[5] Miller DC, Sanda MG, Dunn RL, et al. Long-term outcomes among localized prostate cancer survivors: health-related quality-of-life changes after radical prostatectomy, external radiation, and brachytherapy. J Clin Oncol 2005; 23(12): 2772-80. [http://dx.doi.org/10.1200/JCO.2005.07.116] [PMID: 15837992]

[6] Penson DF, McLerran D, Feng Z, et al. 5-year urinary and sexual outcomes after radical prostatectomy: results from the prostate cancer outcomes study. J Urol 2005; 173(5): 1701-5. [http://dx.doi.org/10.1097/01.ju.0000154637.38262.3a] [PMID: 15821561]

[7] Groutz A, Blaivas JG, Chaikin DC, Weiss JP, Verhaaren M. The pathophysiology of post-radical prostatectomy incontinence: a clinical and video urodynamic study. J Urol 2000; 163(6): 1767-70. [http://dx.doi.org/10.1016/S0022-5347(05)67538-6] [PMID: 10799178]

[8] Porena M, Mearini E, Mearini L, Vianello A, Giannantoni A. Voiding dysfunction after radical retropubic prostatectomy: more than external urethral sphincter deficiency. Eur Urol 2007; 52(1): 38-45. [http://dx.doi.org/10.1016/j.eururo.2007.03.051] [PMID: 17403565]

[9] Guralnick ML, Grimsby G, Liss M, Szabo A, O’Connor RC. Objective differences between overactive bladder patients with and without urodynamically proven detrusor overactivity. Int Urogynecol J Pelvic Floor Dysfunct 2010; 21(3): 325-9.

[http://dx.doi.org/10.1007/s00192-009-1030-7] [PMID: 19907912] 
[10] Ghoniem G, Faruqui N, Elmissiry M, et al. Differential profile analysis of urinary cytokines in patients with overactive bladder. Int Urogynecol J Pelvic Floor Dysfunct 2011; 22(8): 953-61. [http://dx.doi.org/10.1007/s00192-011-1401-8] [PMID: 21487829]

[11] Abdollah F, Sun M, Suardi N, et al. A novel tool to assess the risk of urinary incontinence after nerve-sparing radical prostatectomy. BJU Int 2013; 111(6): 905-13. [http://dx.doi.org/10.1111/j.1464-410X.2012.11560.x] [PMID: 23331334]

[12] Miller RC, Brindle E, Holman DJ, et al. Comparison of specific gravity and creatinine for normalizing urinary reproductive hormone concentrations. Clin Chem 2004; 50(5): 924-32. [http://dx.doi.org/10.1373/clinchem.2004.032292] [PMID: 15105350]

[13] Ralib AM, Pickering JW, Shaw GM, et al. Test characteristics of urinary biomarkers depend on quantitation method in acute kidney injury. J Am Soc Nephrol 2012; 23(2): 322-33. [http://dx.doi.org/10.1681/ASN.2011040325] [PMID: 22095948]

[14] Tesch GH. MCP-1/CCL2: a new diagnostic marker and therapeutic target for progressive renal injury in diabetic nephropathy. Am J Physiol Renal Physiol 2008; 294(4): F697-701. [http://dx.doi.org/10.1152/ajprenal.00016.2008] [PMID: 18272603]

[15] Xia Y, Frangogiannis NG. MCP-1/CCL2 as a therapeutic target in myocardial infarction and ischemic cardiomyopathy. Inflamm Allergy Drug Targets 2007; 6(2): 101-7.

[http://dx.doi.org/10.2174/187152807780832265] [PMID: 17692033]

[16] Liss MA, Skarecky D, Morales B, Ahlering TE. The application of regional hypothermia using transrectal cooling during radical prostatectomy: mitigation of surgical inflammatory damage to preserve continence. J Endourol 2012; 26(12): $1553-7$. [http://dx.doi.org/10.1089/end.2012.0345] [PMID: 23153199]

[17] Finley DS, Osann K, Chang A, Santos R, Skarecky D, Ahlering TE. Hypothermic robotic radical prostatectomy: impact on continence. J Endourol 2009; 23(9): 1443-50.

[http://dx.doi.org/10.1089/end.2009.0411] [PMID: 19698020]

[18] Ficarra V, Novara G, Rosen RC, et al. Systematic review and meta-analysis of studies reporting urinary continence recovery after robotassisted radical prostatectomy. Eur Urol 2012; 62(3): 405-17. [http://dx.doi.org/10.1016/j.eururo.2012.05.045] [PMID: 22749852]

[19] Jeong SJ, Kim HJ, Kim JH, et al. Urinary continence after radical prostatectomy: predictive factors of recovery after 1 year of surgery. Int J Urol 2012; 19(12): 1091-8. [http://dx.doi.org/10.1111/j.1442-2042.2012.03106.x] [PMID: 22846142]

[20] von Bodman C, Matsushita K, Savage C, et al. Recovery of urinary function after radical prostatectomy: predictors of urinary function on preoperative prostate magnetic resonance imaging. J Urol 2012; 187(3): 945-50. [http://dx.doi.org/10.1016/j.juro.2011.10.143] [PMID: 22264458]

[21] Costa Cruz DS, D’Ancona CA, Baracat J, Alves MA, Cartapatti M, Damião R. Parameters of two-dimensional perineal ultrasonography for evaluation of urinary incontinence after Radical Prostatectomy. Int Braz J Urol 2014; 40(5): 596-604. [PMID: 25498270]

[22] Thomas CE, Sexton W, Benson K, Sutphen R, Koomen J. Urine collection and processing for protein biomarker discovery and quantification. Cancer Epidemiol Biomarkers Prev 2010; 19(4): 953-9. [http://dx.doi.org/10.1158/1055-9965.EPI-10-0069] [PMID: 20332277]

[23] Liu HT, Tyagi P, Chancellor MB, Kuo HC. Urinary nerve growth factor but not prostaglandin E2 increases in patients with interstitial cystitis/bladder pain syndrome and detrusor overactivity. BJU Int 2010; 106(11): 1681-5. [http://dx.doi.org/10.1111/j.1464-410X.2009.08851.x] [PMID: 19751258]

(C) Liss et al.; Licensee Bentham Open.

This is an open access article licensed under the terms of the Creative Commons Attribution-Non-Commercial 4.0 International Public License (CC BY-NC 4.0) (https://creativecommons.org/licenses/by-nc/4.0/legalcode), which permits unrestricted, non-commercial use, distribution and reproduction in any medium, provided the work is properly cited. 